\title{
$\alpha$-Endosulfan Removal from Water by Adsorption over Natural Clays from Burkina Faso: An Isothermal Study
}

\author{
Arsène H. Yonli1,2*, Hermann A. Kabore' ${ }^{1}$, Jean Koulidiati1 \\ ${ }^{1}$ Laboratoire de Physique et de Chimie de l'Environnement (LPCE), Université de Ouagadougou, \\ Ouagadougou, Burkina Faso \\ ${ }^{2}$ Yser Lab and Studies, Ouagadougou, Burkina Faso \\ Email: ${ }^{*}$ yarsene@hotmail.com
}

Received 23 September 2014; revised 17 October 2014; accepted 6 November 2014

Copyright (C) 2014 by authors and Scientific Research Publishing Inc.

This work is licensed under the Creative Commons Attribution International License (CC BY). http://creativecommons.org/licenses/by/4.0/

cc) (i) Open Access

\section{Abstract}

The present study carried out the $\alpha$-endosulfan removal from water by adsorption over natural clays from the western region of Burkina Faso. The adsorption experiments were performed over raw clay samples at room temperature in batch reactor and the obtained adsorption isotherms were well fitted by Fowler-Guggenheim model. It was pointed out for all samples that $\alpha$-endosulfan was physisorbed in the interlayer space of the clay samples. The maximal adsorption capacities were respectively about $9.12,6.98$ and $4.13 \mathrm{mg} / \mathrm{g}$ for KO2, KO1 and KW1 samples. The differences in terms of adsorption capacity for the three samples were due to the presence of illite in the samples KO2 and KO1 when the KW1 sample contained essentially kaolinite in its structure. When the interlayer space was large enough as for samples with illite a greater amount of $\alpha$-endosulfan molecules were adsorbed. It was also shown that the samples with the higher surface area were the most efficient for the removal of $\alpha$-endosulfan molecules from water. Moreover, this study exhibited that the $\alpha$-endosulfan adsorption depended on the crystallites size; the samples presenting largest crystallites had the greatest adsorption capacities.

\section{Keywords}

$\alpha$-Endosulfan, Removal, Water, Natural Clays, Burkina Faso

\section{Introduction}

Pesticides are widely used in many countries to increase the crops yield. $\alpha$-endosulfan was extensively used for

"Corresponding author.

How to cite this paper: Yonli, A.H., Kabore, H.A. and Koulidiati, J. (2014) $\alpha$-Endosulfan Removal from Water by Adsorption over Natural Clays from Burkina Faso: An Isothermal Study. Journal of Materials Science and Chemical Engineering, 2, 49-57. 
cotton farming until its prohibition in 2006 in West Africa [1]. But it remains in use because of fraudulent importation of banned pesticides in West African countries. Residues of $\alpha$-endosulfan have been monitored in soils [2] [3], surface and ground waters [4] at levels exceeding the thresholds of $0.10 \mu \mathrm{g} / \mathrm{L}$ adopted by World health Organization (WHO). Such situation is encountered in several countries such as Burkina Faso or Spain [2]-[5]. The toxicity of $\alpha$-endosulfan was clearly documented for humans and animals [6]-[8]. Both toxicological and epidemiological studies [9]-[13] were realized and many diseases such as cancers and neurological affections were identified as potential effects of the exposure to this pesticide. Because of its toxicity and its presence in groundwater, it is suitable to find methods for the removal of $\alpha$-endosulfan from water.

In the literature there are a few papers dealing with low cost methods for the removal of $\alpha$-endosulfan from water. Indeed, the biological treatments [14]-[16] exist, but their implementation for water treatment is difficult at the scale of African villages. The oxidative [17]-[19] and reductive [20] methods are well documented. These methods are generally expensive in the purpose of implementation in rural regions; moreover, they induce the formation of toxic or carcinogenic byproducts. An experience was performed using synthetic zeolites as adsorbents [21] with interesting removal yields of $\alpha$-endosulfan from polluted water. Clay samples were also identified as good candidates for the removal of endosulfan from water [22]. In the purpose of valorization of local materials in Burkina Faso, we decided to investigate the removal efficiency of local clays considered as possible adsorbents for the treatment of water sources contaminated by $\alpha$-endosulfan.

The aim of this paper is to study the removal performances of $\alpha$-endosulfan in water over natural clays from the western region of Burkina Faso.

\section{Experimental}

The clay samples were collected from Kwa and Koro localities in the region of Bobo-Dioulasso (west of Burkina Faso). The Koro site is localized at $11^{\circ} 09^{\prime}$ north latitude and $4^{\circ} 11^{\prime}$ west longitude. Kwa is localized at $11^{\circ} 10^{\prime}$ north latitude and $4^{\circ} 15^{\prime}$ west longitude. According to their texture the samples from Koro site were designated by $\mathrm{KO} 1$ and $\mathrm{KO} 2$ while the sample collected in the Kwa site was designated by KW1. The samples were just sieved to collect particles with size between 0.2 and $0.4 \mathrm{~mm}$; the samples have not undergone any further treatment. The analytical grade of $\alpha$-endosulfan was supplied by Aldrich.

The adsorption experiments of $\alpha$-endosulfan in aqueous solution by the different adsorbents were performed in batch reactor according to the protocol described by Yonli et al. [21] for the adsorptive removal of $\alpha$-endosulfan over zeolites. The experiments were performed at room temperature and atmospheric pressure in $20 \mathrm{~mL}$ tanks. $200 \mathrm{mg}$ of clay were used for each experiment and the initial concentrations of sorbate varied from 10 to $30 \mathrm{mg} / \mathrm{L}$. The concentrations of the solution before adsorption were determined by Varian high performance liquid chromatograph (HPLC) coupled to Varian Prostar 340 UV-Visible detector. The analysis were performed at $1 \mathrm{~mL} / \mathrm{min}$ flow rate on Lichrospher RP 18 column (length $150 \mathrm{~mm}$, internal diameter $4.6 \mathrm{~mm}, 5 \mu \mathrm{m}$ particle size). After determination of initial concentrations, $10 \mathrm{~mL}$ of $\alpha$-endosulfan solution were put into contact with $200 \mathrm{mg}$ of adsorbent and maintained under mechanical stirring until the adsorption equilibrium was achieved. $100 \mu \mathrm{L}$ of supernatant solution were then collected and analyzed by HPLC.

The physico-chemical characteristics of clay samples were obtained by several techniques. The porous volumes and surfaces measurements were performed by nitrogen adsorption at $-196^{\circ} \mathrm{C}$ using a Micromeritics ASAP 2010 analyzer. The surfaces and porous volumes data are reported in Table 1.

The different clay phases present in the samples were determined with a Bruker D5005 diffractometer and the diffractograms are shown in Figures 1(a)-(c) respectively for KO1, KO2, and KW1 samples.

Thermal analysis were realized with a TA instruments DTA-TGA analyzer. The experiments were performed under air flow at $60 \mathrm{~mL} \cdot \mathrm{min}^{-1}$ with an operating temperature ranging from room temperature to $900^{\circ} \mathrm{C}$. The thermograms for the different samples are presented in Figures 2(a)-(c).

Table 1. Surface and porosity characterization of clay samples.

\begin{tabular}{ccc}
\hline Samples & Total Volume $\left(\mathrm{cm}^{\mathbf{3}} \cdot \mathbf{g}^{-\mathbf{1}}\right)$ & BET Surface $\left(\mathbf{m}^{\mathbf{2}} \cdot \mathbf{g}^{-\mathbf{1}}\right)$ \\
\hline KO2 & 0.0034 & 42 \\
KO1 & 0.0037 & 24 \\
KW1 & 0.0021 & 7.9 \\
\hline
\end{tabular}




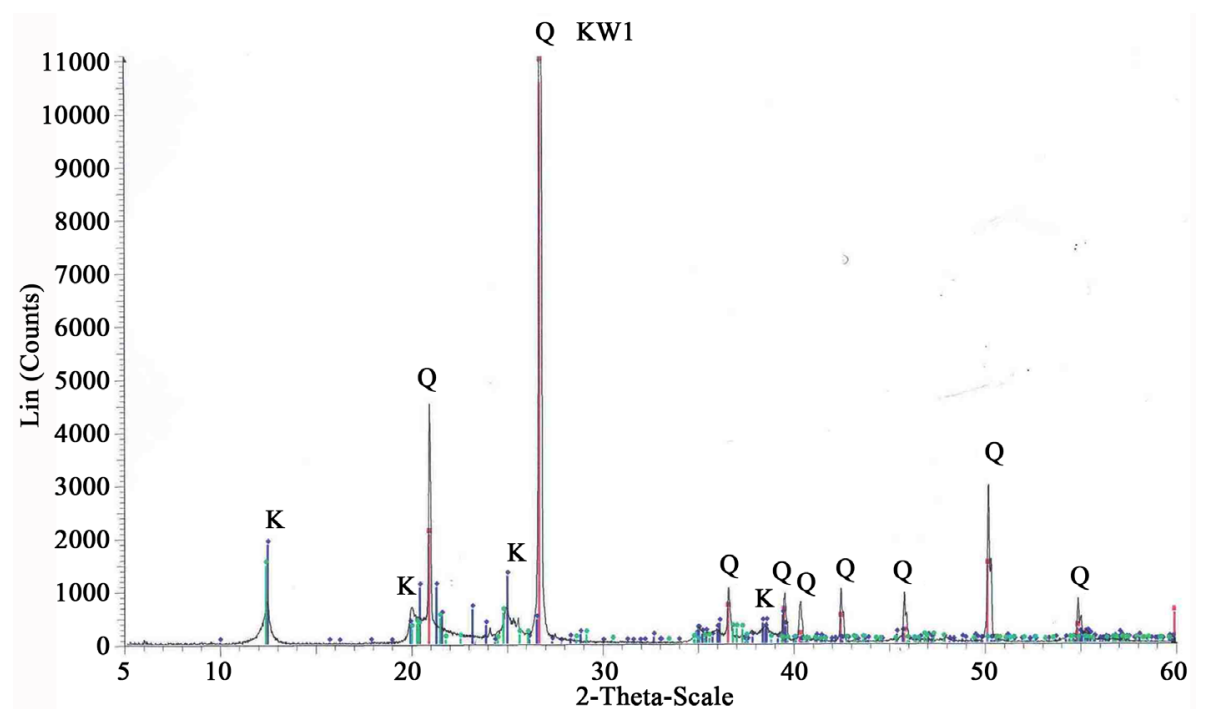

(a)

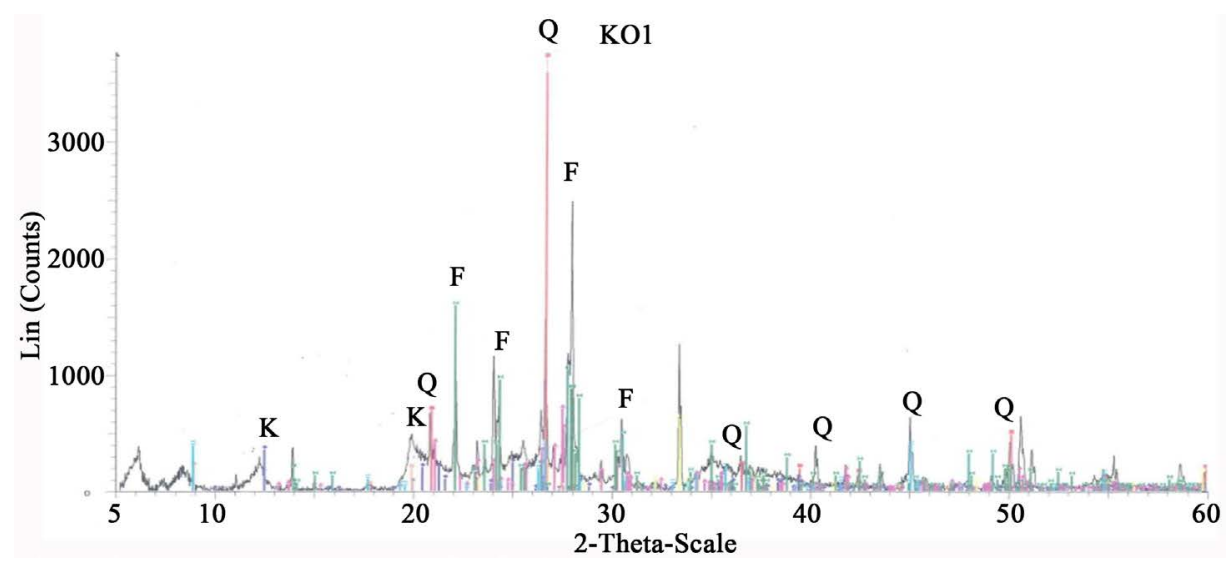

(b)

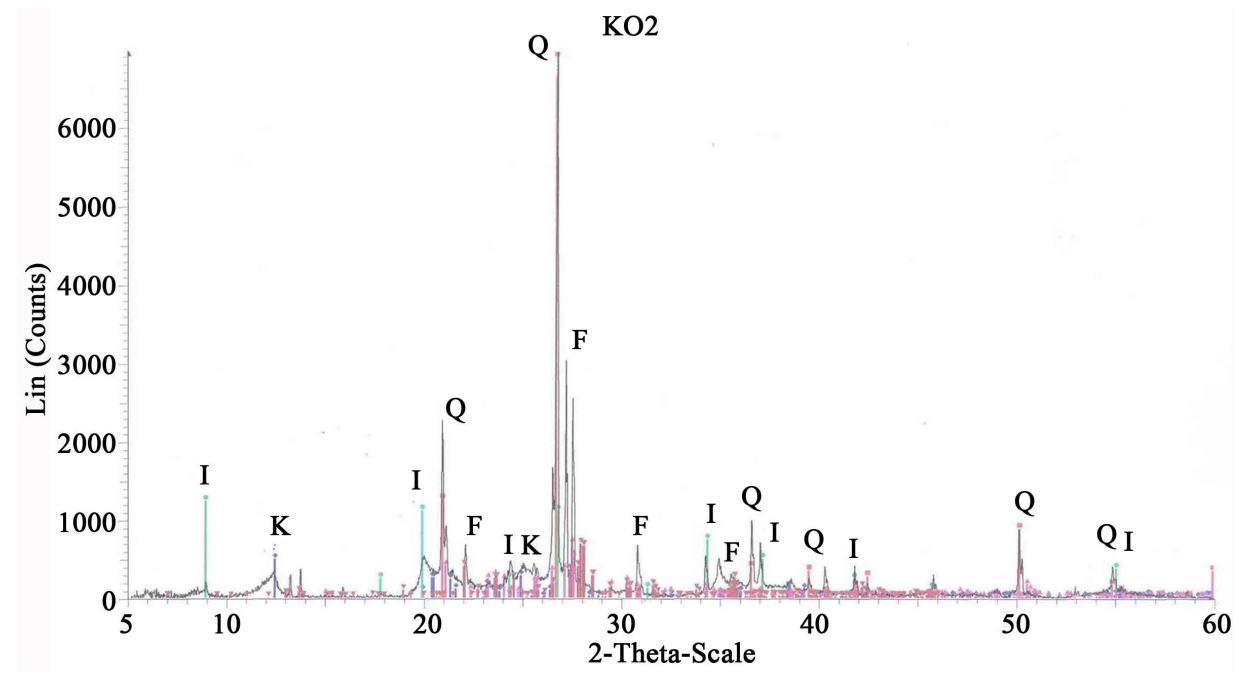

(c)

Figure 1. (a) XRD pattern for KW1 sample; (b) XRD pattern for KO1 sample; (c) XRD pattern for $\mathrm{KO} 2$ sample. 


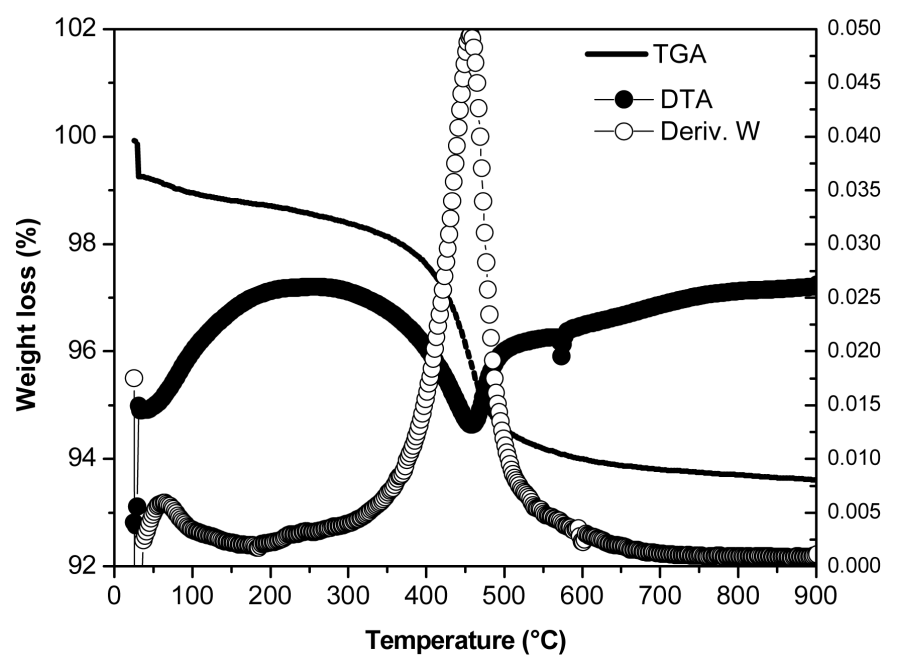

(a)

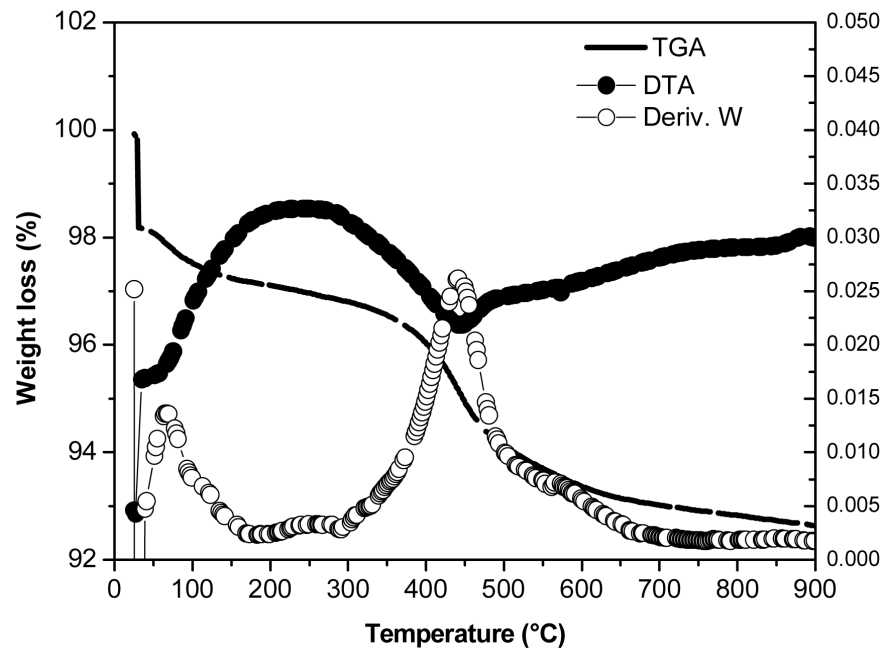

(b)

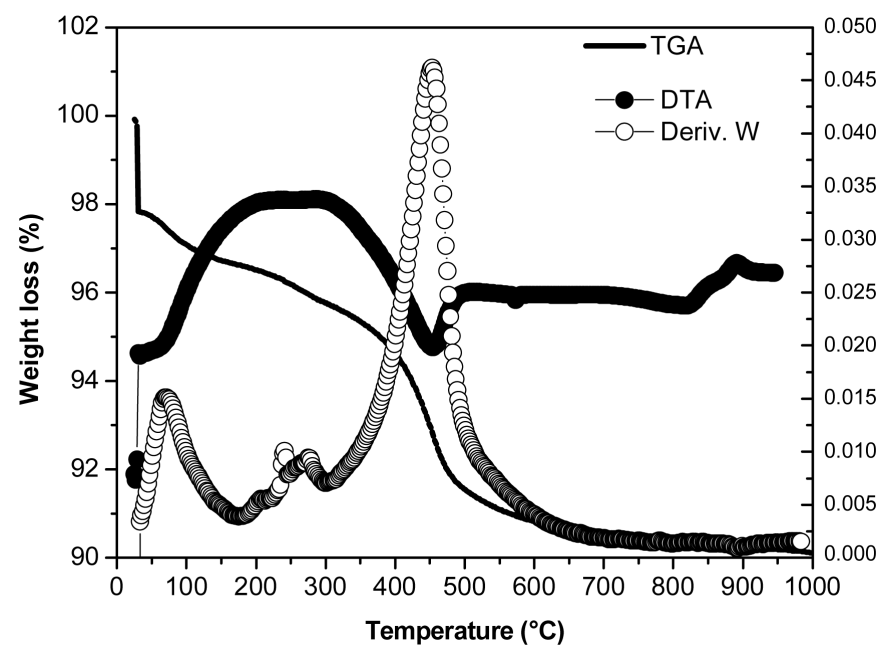

(c)

Figure 2. (a) Thermogram for KW1 sample; (b) Thermogram for KO1 sample; (c) Thermogram for KO2 sample. 
The electronic scanning microscopy was used to estimate the size of the crystallites. The measurements were performed using a high resolution Philips CM 120 microscope. The microscopy images are presented in Figures $3(\mathrm{a})-(\mathrm{c})$.

\section{Results and Discussion}

\subsection{Physico-Chemical Characterization}

As it can be noticed from Table 1 the porous volume for the investigated clay samples was very week $(\sim 0.003$ $\mathrm{cm}^{3} / \mathrm{g}$ ). This denotes that the clay samples had no remarkable pores allowing $\alpha$-endosulfan adsorption in these pores. The specific surface areas for the samples varied in the following order: KO2 $>$ KO1 $>$ KW1. The samples collected in Koro (KO1 and KO2) presented higher specific surface areas than the one from the KWA site (KW1). XRD scans for the same samples as presented in Figures 1(a)-(c) indicate that the KO1 sample consisted mainly in quartz $\alpha$, feldspath, kaolinite, albite and illite; the KO2 sample contained mainly quartz $\alpha$, felds-

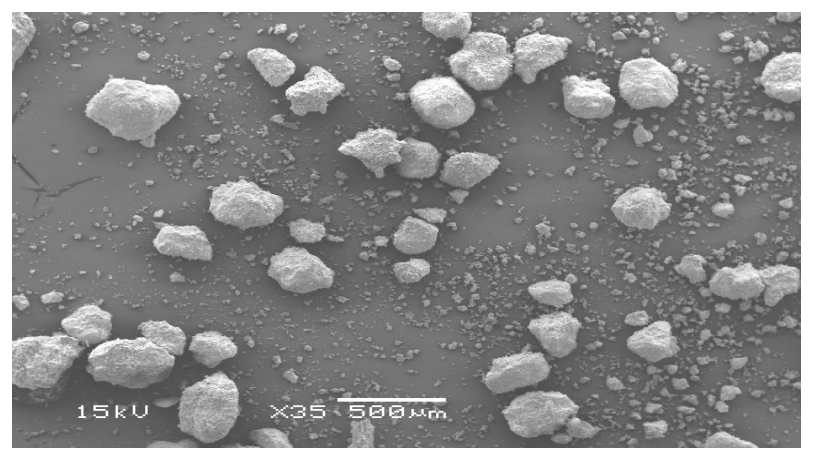

(a)

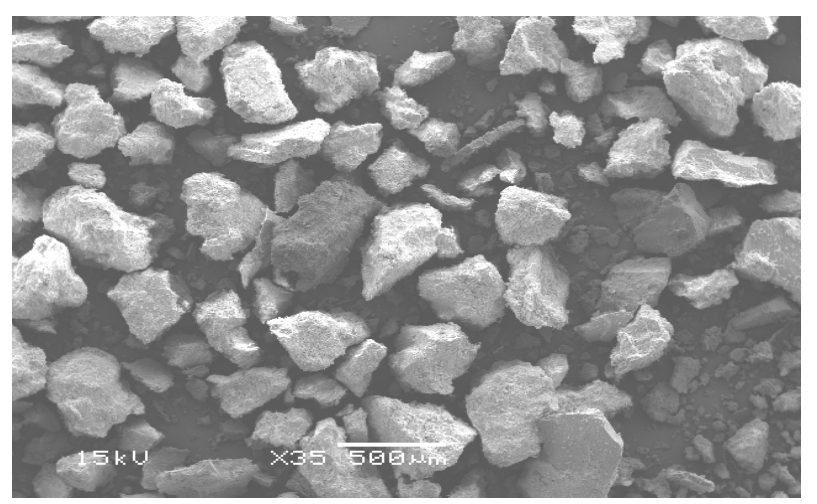

(b)

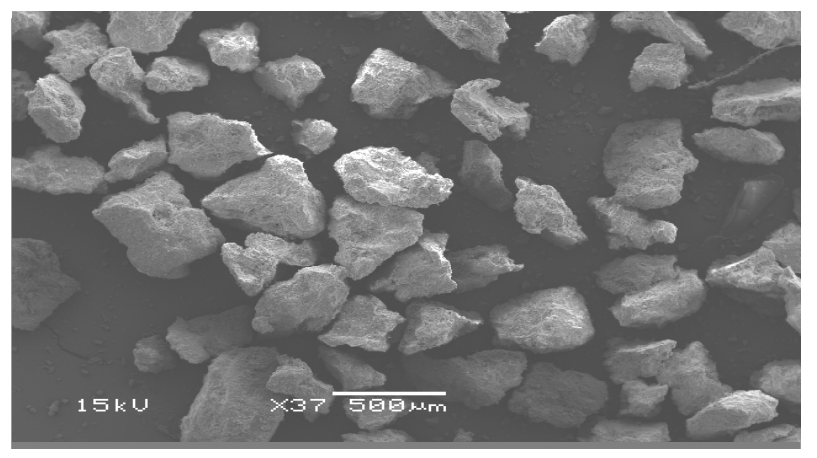

(c)

Figure 3. (a) SEM image for KW1 sample; (b) SEM image for $\mathrm{KO} 1$ sample; (c) SEM image for $\mathrm{KO} 2$ sample. 
path, kaolinite and illite; and the KW1 sample was composed of quartz $\alpha$ and kaolinite. The DTA-TGA thermograms presented in Figures 2(a)-(c) confirmed the existence of some clay phases identified by XRD. Indeed, three endothermic peaks were observed for the $\mathrm{KO} 1$ sample. The first one towards $65^{\circ} \mathrm{C}$ corresponded to the lost of physisorbed and interlayer water. The second peak beginning at $441^{\circ} \mathrm{C}$ was characteristic of the removal of water associated to hydroxyl group degradation in illite samples [23]-[25]. The weak peak at $573^{\circ} \mathrm{C}$ revealed the presence of quartz. In the case of $\mathrm{KO} 2$ sample, three endothermic peaks were also observed. The dehydroxylation of illite starting at $449^{\circ} \mathrm{C}$ was responsible for the second peak. A little hook at $573^{\circ} \mathrm{C}$ characterizing a quartz $\alpha$ to quartz $\beta$ transformation was observed. Likewise the same trend was observed in the case of KW1 sample. However a peak around $455^{\circ} \mathrm{C}$ characterizing the dehydroxylation of kaolinite [26] was also observed for this sample.

The average of crystallites sizes was estimated to be about $510 \mu \mathrm{m}, 420 \mu \mathrm{m}$ and $335 \mu \mathrm{m}$ respectively for $\mathrm{KO}$, KO1 and KW1 samples as it can be observed from Figures 3(a)-(c). In the literature the crystallite size is generally correlated to the number of silanol groups. The biggest particles have less silanol groups and therefore adsorb less water molecules on their external surface [27]. Basing upon the crystallites size the following classification in terms of water adsorption capacities was expected: KO2 > KO1 > KW1.

\section{2. $\alpha$-Endosulfan Adsorption on Clays}

The $\alpha$-endosulfan adsorption isotherms for KO2, KO1 and KW1 clay samples are represented in Figure 4.

According to the classification of Giles [28], these isotherms are S-type isotherms. This specific shape of isotherms indicated weak sorbate-adsorbent interactions. Moreover the adsorption isotherms were well fitted by Fowler-Guggenheim [29] model. From this modelization different parameters such as maximal adsorption capacity, sorbate-sorbate interaction energy $(\mathrm{W})$ and sorbate-adsorbent interaction constant $(\mathrm{K})$ could be determined. These data are reported in Table 2 and exhibited that sorbate-adsorbent interactions were stronger for KW1 (kaolinite containing sample) and progressively lower for KO1 and KO2 (samples with illite phases).

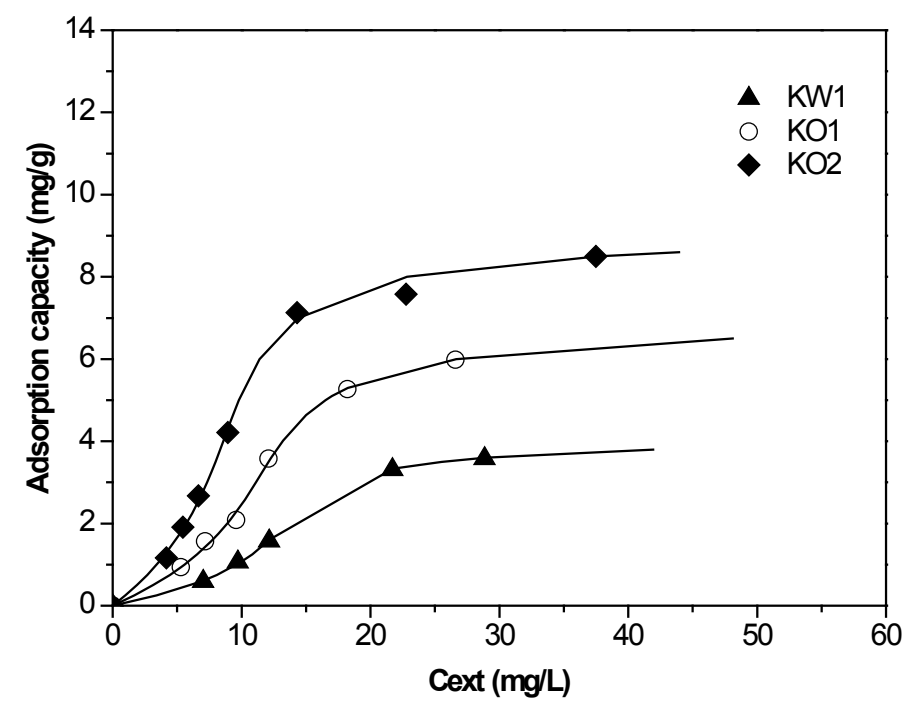

Figure 4. Adsorption isotherms of $\alpha$-endosulfan over KW1, KO1 and $\mathrm{KO} 2$ clay samples.

Table 2. Fowler-Guggenheim parameters for the adsorption of $\alpha$-endosulfan over raw clay samples collected in western Burkina Faso.

\begin{tabular}{|c|c|c|c|}
\hline Samples & $\begin{array}{l}\text { Maximal Adsorption } \\
\text { Capacity (mg/g) }\end{array}$ & $\begin{array}{c}\text { Sorbate-Adsorbent } \\
\text { Interaction Constant K }\end{array}$ & $\begin{array}{c}\text { Sorbate-Sorbate } \\
\text { Interaction Energy W }\left(\mathbf{K J} \cdot \mathrm{mol}^{-1}\right)\end{array}$ \\
\hline KW1 & 4.13 & 63.98 & 3.10 \\
\hline KO1 & 6.98 & 49.92 & 2.83 \\
\hline $\mathrm{KO} 2$ & 9.12 & 37.68 & 2.81 \\
\hline
\end{tabular}


As reported by Yonli et al. [21] the diameter of $\alpha$-endosulfan molecule is estimated to be about $7.2 \AA$. This value is close to the interlayer space of kaolinite (about $7 \AA$ ). So the physisorption of $\alpha$-endosulfan in the interlayer of the KW1 sample is slightly enhanced by Van Der Waals Interactions between sorbate and solid. In the case of samples with illite phases the interlayer space is wider $(10 \AA)$ and the $\alpha$-endosulfan molecules are more easily absorbed in the interlayer space with less interactions between $\alpha$-endosulfan molecules and adsorbent (lower sorbate-adsorbent interactions constants for KO1 and KO2). A slight variation of sorbate-sorbate interaction energy was noticed for the three samples. Indeed the first molecules to be adsorbed in the interlayer space promote the adsorption of new molecules by lateral interactions between adsorbed molecules [30]. When the interlayer space is narrow the adsorbed molecules are cramped and confined in the interlayer inducing thus more interactions between adsorbed molecules. A ranking of maximal adsorption capacities was obtained and presented as follows: KO2 $>\mathrm{KO} 1>\mathrm{KW} 1$. The higher adsorption capacities noticed for clay samples collected in the Koro site were due to the presence of illite phases in these samples. The KW1 sample had the lower adsorption capacity due to the presence of kaolinite in the structure. As the KO2 sample had a higher specific surface area than the KO1 sample the adsorption capacity for KO2 sample was more important. Indeed we had a BET surface area of about $42 \mathrm{~m}^{2} / \mathrm{g}$ for KO2, almost two times higher than the one for KO1 $\left(24 \mathrm{~m}^{2} / \mathrm{g}\right)$.

Figure 5 indicates that the $\alpha$-endosulfan adsorption capacities increase linearly with the crystallites size.

Indeed, the big crystallites have less terminal silanol groups than the small crystallites [31] and are consequently more hydrophobic. This hydrophobic character of samples containing big crystallites promotes the adsorption of organic molecules such as $\alpha$-endosulfan in water [32] when adsorption is performed over solid samples. The KO2 sample with crystallites size of about $510 \mu \mathrm{m}$ is thus the most efficient for the removal of $\alpha$-endosulfan in water compared to KO1 and KW1 samples.

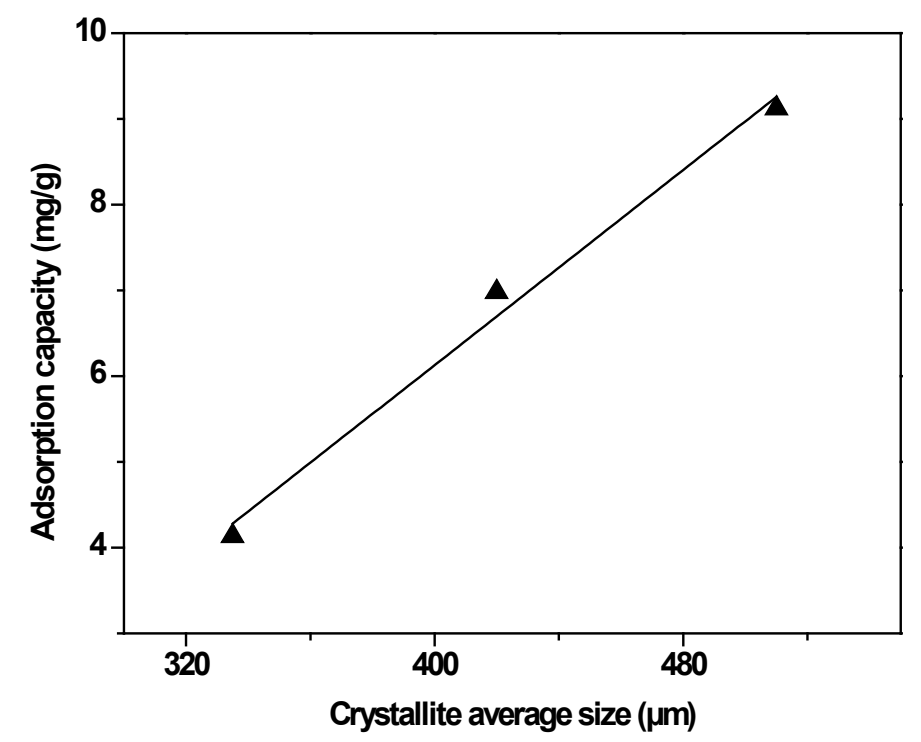

Figure 5. Evolution of $\alpha$-endosulfan adsorption capacity versus crystallite average size for $\mathrm{KW} 1, \mathrm{KO} 1$ and $\mathrm{KO} 2$ clay samples.

\section{Conclusion}

The $\alpha$-endosulfan adsorption was studied on clay samples collected from two sites in the western part of Burkina Faso. A part from mechanical sieving no further treatment was applied to the raw samples. The physico-chemical characterization showed three types of samples: the KO2 sample containing illite phases and big crystallites, the KO1 sample with illite phases and smaller crystallites and the KW1 sample with kaolinite phases and the smallest crystallites. The $\alpha$-endosulfan molecules were physisorbed in the interlayer space of clay samples with Van Der Waals Interactions. The nature of clay phases, the surface BET area and the size of crystallites influenced the adsorption of $\alpha$-endosulfan over natural raw clays samples. The most efficient sample for the removal of $\alpha$-endosulfan in water was the KO2 sample with illite phases, the largest surface area and the biggest crystallites. 


\section{Acknowledgements}

Arsène H. Yonli would like to thank the International Foundation for Science (IFS) for the grant given to support this study.

\section{References}

[1] CILSS (2007) Decision No. 0691/MC/2007 for Prohibition of Endosulfan. Permanent Interstate Committee for Drought Control in the Sahel, Ouagadougou.

[2] Castro, J., Pérez, R.A., Miguel, E., Sánchez-Brunete, C. and Tadeo, J.L. (2002) Analysis of Endosulfan Isomers and Endosulfan Sulfate in Air and Tomato Leaves by Gas Chromatography with Electron-Capture Detection and Confirmation by Gas Chromatography-Mass Spectrometry. Journal of Chromatography A, 947, 119-127. http://dx.doi.org/10.1016/S0021-9673(01)01598-9

[3] Lopez-Espinosa, M.-J., Lopez-Navarrete, E., Rivas, A., Fernandez, M.F., Nogueras, M., Campoy, C., Olea-Serrano, F., Lardelli, P. and Olea, N. (2008) Organochlorine Pesticide Exposure in Children Living in Southern Spain. Environmental Research, 106, 1-6. http://dx.doi.org/10.1016/j.envres.2007.08.001

[4] Cerrillo, I., Olea-Serrano, M.F., Ibarluzea, J., Exposito, J., Torne, P., Laguna, J., Pedraza, V. and Olea, N. (2006) Environmental and Lifestyle Factors for Organochlorine Exposure among Women Living in Southern Spain. Chemosphere, 62, 1917-1924. http://dx.doi.org/10.1016/j.chemosphere.2005.07.024

[5] Tapsoba, H.K. and Bonzi-Coulibaly, Y.L. (2006) Production cotonnière et Pollution des eaux par les pesticides au Burkina Faso. Journal de la Société Ouest-Africaine de Chimie, 21, 87-93.

[6] Caride, A., Lafuente, A. and Cabaleiro T. (2010) Endosulfan Effects on Pituitary Hormone and Both Nitrosative and Oxidative Stress in Pubertal Male Rats. Toxicology Letters, 197, 106-112. http://dx.doi.org/10.1016/j.toxlet.2010.05.006

[7] Silva, M.H. and Beauvais, S.L. (2010) Human Health Risk Assessment of Endosulfan. I: Toxicology and Hazard Identification. Regulatory Toxicology and Pharmacology, 56, 4-17. http://dx.doi.org/10.1016/j.yrtph.2009.08.013

[8] Briz, V., Molina-Molina, J.M., Caballero, B., Fernández, M., Olea, N., Rodríguez-Farre, E. and Suñol, C. (2010) Estrogenic Effects of the Endocrine Disruptors Dieldrin, Endosulfan and Lindane in Neuronal Cultures. Toxicology Letters, 196, 317.

[9] Hiremath, M.B. and Kaliwal, B.B. (2002) Effect of Endosulfan on Ovarian Compensatory Hypertrophy in Hemicastrated Albino Mice. Reproductive Toxicology, 16, 783-790.

[10] Silva, M.H. and Carr Jr., W.C. (2010) Human Health Risk Assessment of Endosulfan: II. Dietary Exposure Assessment. Regulatory Toxicology and Pharmacology, 56, 18-27 http://dx.doi.org/10.1016/j.yrtph.2009.08.015

[11] Botella, B., Crespo, J., Rivas, A., Cerrillo, I., Olea-Serrano, M.F. and Olea, N. (2004) Exposure of Women to Organochlorine Pesticides in Southern Spain. Environmental Research, 96, 34-40. http://dx.doi.org/10.1016/i.envres.2003.10.001

[12] Aggarwal, M., Naraharisetti, S.B., Dandapat, S., Degen, G.H. and Malik, J.K. (2008) Perturbations in Immune Responses Induced by Concurrent Subchronic Exposure to Arsenic and Endosulfan. Toxicology, 251, 51-60.

[13] Wang, X.-F., Li, S., Chou, A.P. and Bronstein, J.M. (2006) Inhibitory Effects of Pesticides on Proteasome Activity: Implication in Parkinson's Disease. Neurobiology of Disease, 23, 198-205. http://dx.doi.org/10.1016/j.nbd.2006.02.012

[14] Aslan, S. and Türkman, A. (2004) Simultaneous Biological Removal of Endosulfan $(\alpha+\beta)$ and Nitrates from Drinking Waters Using Wheat Straw as Substrate. Environmental Internships, 30, 449-455. http://dx.doi.org/10.1016/S0160-4120(03)00092-8

[15] Silambarasan, S. and Abraham, J. (2014) Halophilic Bacterium JAS4 in Biomineralisation of Endosulfan and Its Metabolites Isolated from Gossypium herbaceum Rhizosphere Soil. Journal of the Taiwan Institute of Chemical Engineers, 45, 1748-1756. http://dx.doi.org/10.1016/j.jtice.2014.01.013

[16] Guerin, T.F. (2001) A Biological Loss of Endosulfan and Related Chlorinated Organic Compounds from Aqueous Systems in the Presence and Absence of Oxygen. Environmental Pollution, 115, 219-230. http://dx.doi.org/10.1016/S0269-7491(01)00112-9

[17] López, E., Ordóñez, S., Sastre, H. and Díez, F.V. (2003) Kinetic Study of the Gas-Phase Hydrogenation of Aromatic and Aliphatic Organochlorinated Compounds Using a $\mathrm{Pd} / \mathrm{Al}_{2} \mathrm{O}_{3}$ Catalyst. Journal of Hazardous Materials, 97, 281294.

[18] Cañizares, P., Lobato, J., Paz, R., Rodrigo, M.A. and Sáez, C. (2005) Electrochemical Oxidation of Phenolic Wastes with Boron-Doped Diamond Anodes. Water Research, 39, 2687-2703. http://dx.doi.org/10.1016/j.watres.2005.04.042

[19] Manoj Kumar Reddy, P., Mahammadunnisa, S. and Subrahmanyam, C. (2014) Catalytic Non-Thermal Plasma Reactor 
for Mineralization of Endosulfan in Aqueous Medium: A Green Approach for the Treatment of Pesticide Contaminated Water. Chemical Engineering Journal, 238, 157-163. http://dx.doi.org/10.1016/j.cej.2013.08.087

[20] Thangadurai, P. and Suresh, S. (2013) Reductive Transformation of Endosulfan in Aqueous Phase Using Magnesium-Palladium Bimetallic Systems: A Comparative Study. Journal of Hazardous Materials, 246-247, 245-256.

http://dx.doi.org/10.1016/j.jhazmat.2012.12.031

[21] Yonli, A.H., Batonneau-Gener, I. and Koulidiati, J. (2012) Adsorptive Removal of $\alpha$-Endosulfan from Water by Hydrophobic Zeolites. An Isothermal Study. Journal of Hazardous Materials, 203-204, 357-362. http://dx.doi.org/10.1016/j.jhazmat.2011.12.042

[22] Rauf, N., Tahir, S.S., Kang, J.-H. and Chang, Y.-S. (2012) Equilibrium, Thermodynamics and Kinetics Studies for the Removal of Alpha and Beta Endosulfan by Adsorption onto Bentonite Clay. Journal of Hazardous Materials, 192, 369-376. http://dx.doi.org/10.1016/j.cej.2012.03.047

[23] Gourouza, M., Zanguina, A., Natatou, I. and Boos, A. (2013) Characterization of a Mixed Clay Niger. Revue CAMES-Sciences et Structure de la Matière, 1, 29-39.

[24] Wolters, F. and Emmerich, K. (2007) Thermal Reactions of Smectites-Relation of Dehydroxylation Temperature to Octahedral Structure. Thermochimica Acta, 462, 80-88. http://dx.doi.org/10.1016/j.tca.2007.06.002

[25] Drits, V.A., Besson, G. and Muller, F. (1995) An Improved Model for Structural Transformations of Heat-Treated Aluminous Dioctahedral 2:1 Layer Silicates. Clays and Clay Minerals, 43, 718-731. http://dx.doi.org/10.1346/CCMN.1995.0430608

[26] Kabre, T.S., Traore, K. and Blanchard, P. (1998) Mineralogy of Clay Raw Material from Burkina Faso and Niger Used for Ceramic Wares. Applied Clay Science, 12, 463-477. http://dx.doi.org/10.1016/S0169-1317(98)00005-2

[27] Batonneau-Gener, I., Yonli, A., Trouvé, A., Mignard, S., Guidotti, M. and Sgobba, M. (2010) Tailoring the Hydrophobic Character of Mesoporous Silica by Silylation for VOC Removal. Separation Science and Technology, 45, 768775. http://dx.doi.org/10.1080/01496391003609155

[28] Giles, C.H., Smith, D. and Huitson, A. (1974) A General Treatment and Classification of the Solute Adsorption Isotherm. I. Theoretical. Journal of Colloid and Interface Science, 47, 755-765. http://dx.doi.org/10.1016/0021-9797(74)90252-5

[29] Fowler, R.H. and Guggenheim, E.A. (1949) Statistical Thermodynamics. Cambridge University Press, Cambridge, 431-450.

[30] Yonli, A.H., Khalid, M., Batonneau-Gener, I., Koulidiati, J., Joly, G., Magnoux, P. and Mignard, S. (2011) Removal of Phenolic Pollutants from Water over BEA and HY Zeolites in Batch Conditions. Journal of Chemistry and Chemical Engineering, 5, 429-434.

[31] Yonli, A.H., Gener, I. and Mignard, S. (2009) Influence of Post-Synthesis Treatment on BEA Zeolites Hydrophobicity Assessed under Static and Dynamic Conditions. Microporous and Mesoporous Materials, 122, 135-142.

[32] Yonli, A.H., Gener, I. and Mignard, S. (2010) Comparative Study of the Hydrophobicity of BEA, HZSM-5 and HY Zeolites Determined by Competitive Adsorption. Microporous and Mesoporous Materials, 132, 37-42. http://dx.doi.org/10.1016/j.micromeso.2009.08.007 
Scientific Research Publishing (SCIRP) is one of the largest Open Access journal publishers. It is currently publishing more than 200 open access, online, peer-reviewed journals covering a wide range of academic disciplines. SCIRP serves the worldwide academic communities and contributes to the progress and application of science with its publication.

Other selected journals from SCIRP are listed as below. Submit your manuscript to us via either submit@scirp.org or Online Submission Portal.
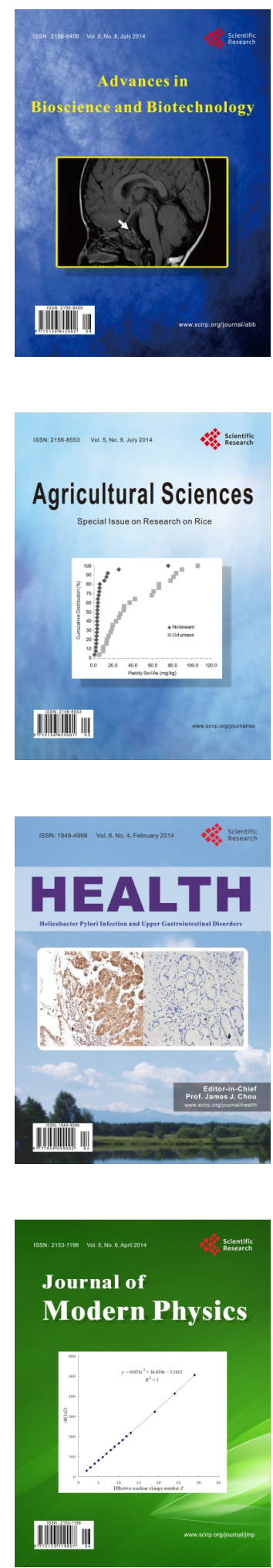
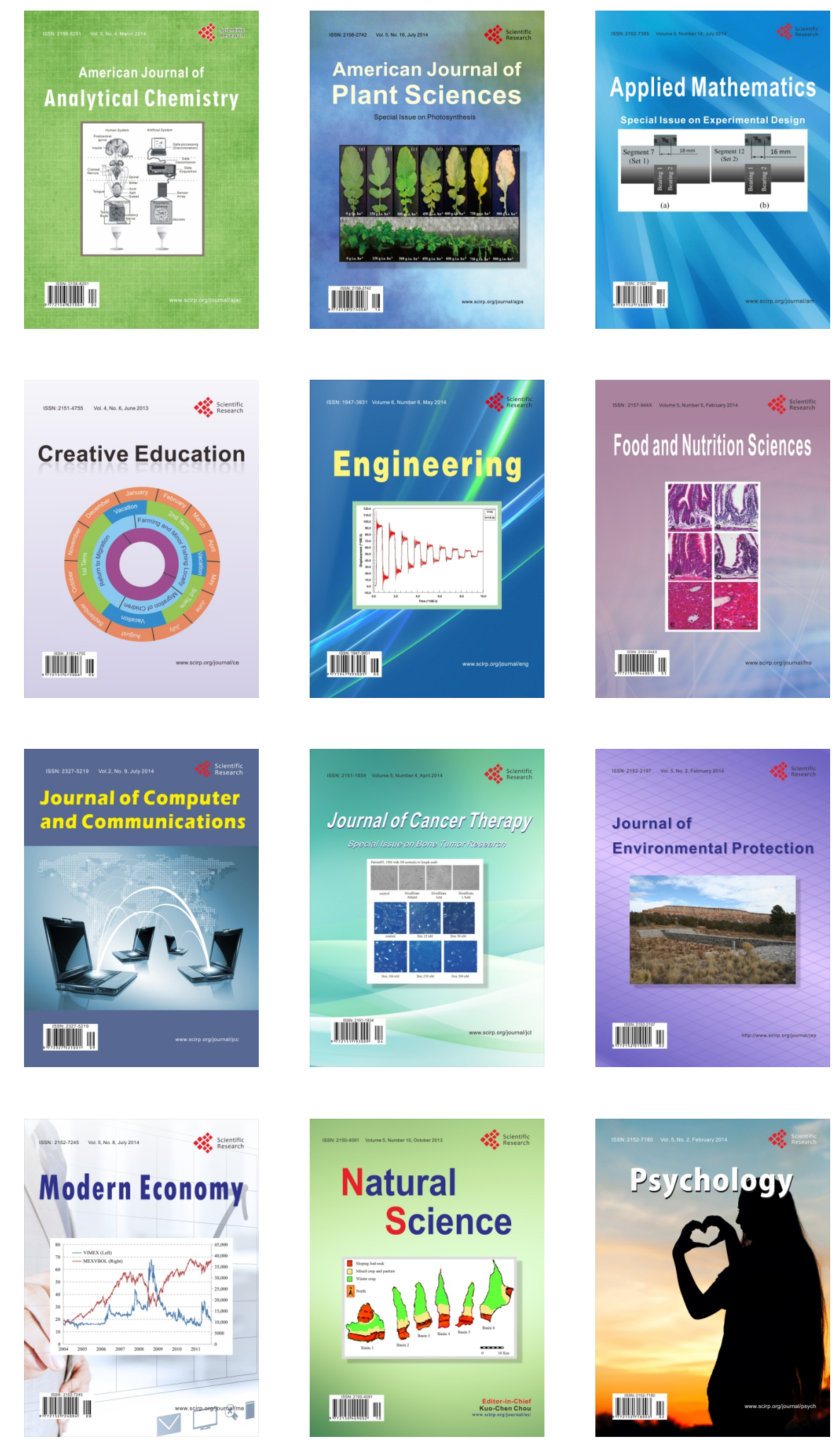